\title{
SHARP INEQUALITIES FOR HILBERT TRANSFORM IN A VECTOR-VALUED SETTING
}

\author{
ADAM OSȨKOWSKI
}

Abstract. The paper is devoted to the study of the periodic Hilbert transform $\mathscr{H}$ in the vector valued setting. Precisely, for any positive integer $N$ we determine the norm of $\mathscr{H}$ as an operator from $L^{\infty}\left(\mathbb{T} ; \ell_{\infty}^{N}\right)$ to $L^{p}\left(\mathbb{T} ; \ell_{\infty}^{N}\right), 1 \leqslant p<\infty$, and from $L^{p}\left(\mathbb{T} ; \ell_{1}^{N}\right)$ to $L^{1}\left(\mathbb{T} ; \ell_{1}^{N}\right)$, for $1<p \leqslant \infty$. The proof rests on the existence of a certain family of special harmonic functions.

Mathematics subject classification (2010): 31B05, 60G44.

Keywords and phrases: Hilbert transform, martingale, best constants.

\section{REFERENCES}

[1] D. J. Aldous, Unconditional bases and martingales in $L_{p}(F)$, Math. Proc. Cambridge Phil. Soc. 85 (1979), 117-123.

[2] R. BAÑUELOS AND G. WANG, Sharp inequalities for martingales with applications to the BeurlingAhlfors and Riesz transformations, Duke Math. J. 80 (1995), 575-600.

[3] R. BAÑUELOS AND G. WANG, Davis's inequality for orthogonal martingales under differential subordination, Michigan Math. J. 47 (2000), 109-124.

[4] S. BOCHNER AND A. E. TAYLOR, Linear functionals on certain spaces of abstractly-valued functions, Ann. Math. 39 (1938), 913-944.

[5] J. Bourgain, Some remarks on Banach spaces in which martingale difference sequences are unconditional, Ark. Mat. 21 (1983), 163-168.

[6] J. Bourgain, Extension of a result of Benedek, Calderon, and Panzone, Ark. Mat. 22 (1981), 91-95.

[7] D. L. BURKHOLDER, A geometrical e aracterization of Banach spaces in which martingale difference sequences are unconditional, Ann. Probab. 9 (1981), 997-1011.

[8] D. L. BURKHOLDER, Martingale transforms and the geometry of Banach spaces, Proceedings of the Third International Conference on Probability in Banach Spaces, Tufts University, 1980, Lecture Notes in Mathematics 860 (1981), 35-50.

[9] D. L. BURKHOLDER, A geometric condition that implies the existence of certain singular integrals of Banach-space-valued functions, Conference on Harmonic Analysis in Honor of Antoni Zygmund, University of Chicago, 1981, Wadsworth International Group, Belmont, California (1983), 270-286.

[10] D. L. BURKHOLDER, Martingales and singular integrals in Banach spaces, Handbook of the Geometry of Banach Spaces, Vol. 1, 2001, 233-269.

[11] A. P. CAlderón ANd A. Zygmund, On singular integrals, Amer. J. of Math. 78 (1956), 289-309.

[12] B. Davis, On the weak type $(1,1)$ inequality for conjugate functions, Proc. Amer. Math. Soc. 44 (1974), 307-311.

[13] C. Dellacherie And P. A. Meyer, Probabilities and potential B, North-Holland, Amsterdam, 1982.

[14] E. M. EsSÉN, A superharmonic proof of the M. Riesz conjugate function theorem, Ark. Mat. 22 (1984), 241-249.

[15] M. Essén, D. F. SheA And C. S. StAnton, Best constants in Zygmund's inequality for conjugate functions, A volume dedicated to Olli Martio on his 60th birthday (ed. Heinonen, Kilpeläinen and Koskela), report 83 (2001), Department of Mathematics, University of Jyväskila, 73-80.

[16] M. Essén, D. F. SheA And C. S. StAnton, Sharp $L \log ^{\alpha} L$ inequalities for conjugate functions, Ann. Inst. Fourier, Grenoble 52, (2002), 623-659. 
[17] I. Gohberg And N. KRupnik, Norm of the Hilbert transformation in the $L_{p}$ space, Funct. Anal. Pril. 2 (1968), 91-92 [in Russian]; English transl. in Funct. Anal. Appl. 2 (1968), 180-181.

[18] P. JANAKIRAMAN, Best weak-type $(p, p)$ constants, $1 \leqslant p \leqslant 2$ for orthogonal harmonic functions and martingales, Illinois J. Math. 48 (2004), 909-921.

[19] T. R. MCCONNELL, On Fourier multiplier transformations of Banach-valued functions, Trans. Amer. Math. Soc. 285 (1984), 739-757.

[20] A. OSȨKOWSKI, Sharp inequalities for differentially subordinate harmonic functions and martingales, Canadian Math. Bull. 55 (2012), 597-610.

[21] A. OsȩKowsKi, Sharp logarithmic inequalities for Riesz transforms, J. Funct. Anal. 263 (2012), 89-108.

[22] S. K. Pichorides, On the best values of the constants in the theorems of M. Riesz, Zygmund and Kolmogorov, Studia Math. 44 (1972), 165-179.

[23] M. RiEsz, Les fonctions conjugées et ler séries de Fourier, C. R. Acad. Paris 178 (1924), 1464-1467.

[24] M. RiESZ, Sur les fonctions conjugées, Math. Z. 27 (1927), 218-244.

[25] J. L. RUBIO DE FRANCIA, Fourier series and Hilbert transforms with values in UMD Banach spaces, Studia Math. 81 (1985), 95-105.

[26] B. TomASZEWS KI, Some sharp weak-type inequalities for holomorphic functions on the unit ball of $\mathbb{C}^{n}$, Proc. Amer. Math. Soc. 95 (1985), 271-274.

[27] G. WANG, Differential subordination and strong differential subordination for continuous time martingales and related sharp inequalities, Ann. Probab. 23 (1995), 522-551. 